\title{
The role of glucosylceramide and glucosylceramide synthase in liver disease: from bench to bedside
}

\author{
Jian Gan', Su Jun Zheng², Xiao Rong Mao ${ }^{1,3 \square}$ and Jun Feng Li1,3,4⿴ \\ 1The First Clinical Medical College of Lanzhou University, Lanzhou 730000, China; ${ }^{2}$ Artificial Liver Center, Beijing YouAn Hospital, Capital Medical \\ University, Beijing 100000, China; ${ }^{3}$ Department of Infectious Diseases, The First Hospital of Lanzhou University, Lanzhou 730000, China; ${ }^{4}$ nstitute \\ of Infectious Diseases, The First Hospital of Lanzhou University, Lanzhou 730000, China
}

The cell membrane, which is lipid-rich, is not only a simple mechanical barrier but also an important and complex component of the cell. It also communicates with the external environment. Sphingomyelin is an important class of phospholipids in the membrane that performs many functions. Interest in sphingomyelinbased liposomes, which are a critical component of cell membranes, have become the focus of intense study in recent years. Through additional research, the function of sphingomyelin and its derivatives in diseases can be gradually elucidated. Sphingomyelin consists of ceramide and its derivatives including ceramide-1-phosphate glucosylceramide and sphingosine-1-phosphate. The metabolism of glucosylceramide is regulated by glucosylceramide synthase (EC: 2.4.1.80) which is the key enzyme in the glycosylation of ceramide. The activity of glucosylceramide synthase directly affects the level of glucosylceramide in cells which in turn affects the function of cells and may eventually lead to diseases. Recently, the relationship between glucosylceramide and its metabolic enzymes, with diseases has become a relatively new area of study. The purpose of this paper is to address the relationship between glucosylceramide, glucosylceramide synthase, and their possible association with liver diseases at the theoretical level.

Key words: glucosylceramide; glucosylceramide synthase; uridine diphosphate glucosylceramide glucosyltransferase; hepatitis; liver fibrosis; hepatocellular carcinoma

Received: 04 September, 2020; revised: 02 October, 2020; accepted: 03 October, 2020; available on-line: 27 December, 2020

Ðe-mail: junfenglee@126.com (JFL); mxr2013@126.com (XRM)

Acknowledgment of Financial Support: This work was supported by grants from the National Natural Science Foundation of China (81800528); Natural Science Foundation of Gansu Province (20JR5RA364); Key Research and Development Project of Gansu Province (2OYF2FA011); the Scientific Research Projects of the Universities in Gansu Province (2018B-009); the Hospital Fund from the First Hospital of Lanzhou University (Idyyyn2017-17); the Gansu Health Industry Research Project (GSWSKY2018-24); the Science and Technology Development Project of Chengguan District (2018SHFZ0023); and the National Science and Technology Key Project(2017ZX10201201, 2017ZX10203201-005, 2017ZX10202203006-001 and 2017ZX10302201-004-002).

Abbreviations: Ceramide (Cer); Glucosylceramide (GC); Glucosylceramide synthase (GCS); UDP-glucose ceramide glucosyltransferase (UGCG); Natural killer T cell (NKT); Concanavalin A (ConA); Hepatocellular carcinoma (HCC).

\section{INTRODUCTION}

There are many kinds of lipids found in eukaryotic membranes which are unevenly distributed. Each membrane region performs a unique function (Jin et al., 2019). For example, the secretory process of cells needs to go through different membrane structures for translocation and exchange to occur between organelles (Mesmin et al., 2016). The cell membrane and organelle membrane not only act as a barrier but also play an important and complex role. The membrane is also interacting with external environments. They participate in many physiological and pathological processes of cells. For example, the host's response to infection may manifest as altered membrane lipid metabolism. Our previous research results showed that plasma sphingomyelin is elevated in patients with chronic hepatitis $C$ virus infection and is closely linked to liver steatosis ( $\mathrm{Li}$ et al., 2014). The sphingolipids are an important component of cell membranes, they are related to the fluidity of the cell membrane and the maintenance of the subregional structures, which is important for the cell membrane to perform various functions (Slotte et al., 2013; AhumadaGutierrez et al., 2019).

Recently, the possible association between sphingolipids and liver diseases has become the focus of intense research (Apostolopoulou et al., 2018). Our research has shown that sphingolipids play an important role in the occurrence and development of liver diseases and that the plasma sphingomyelin is closely related to viral hepatitis (Li et al., 2014; Li et al., 2014; Zheng et al., 2015; Zhang et al., 2016). Plasma sphingolipids may also be potential biomarkers for severe hepatic fibrosis ( $\mathrm{Li}$ et al., 2015). The glycosphingolipid is the product of the glycosylation of a sphingolipid and one of the components of cell membrane lipids. The biological functions of sphingolipids and their related enzymes involved in metabolic processes are gradually being elucidated. Glucosylceramide (GC) is the product of D-glucose and ceramide (Cer) transglycosylation as catalyzed by glucosylceramide synthase (GCS). GCS also called UDP-glucose ceramide glucosyltransferase (UGCG) is the key enzyme that catalyzes the first glycosylation step in glycosphingolipid biosynthesis. Its activity determines the balance of intracellular Cer/GC which can affect the functional state of cells (Marshall et al., 2019).

\section{THE STRUCTURE AND FUNCTION OF GC/GCS}

As a glycosylated derivative of Cer, GC synthesis begins with the hydrolysis of sphingomyelin, while sphingomyelin synthesis begins with serine and palmitate. The basic structure of sphingomyelin consists of a phosphocholine head group, a sphingosine backbone, and a fatty acid tail (Apostolopoulou et al., 2018) (Fig. 1). The phosphocholine head defines different kinds of sphingomyelin, resulting from distinct molecular group modifications. 


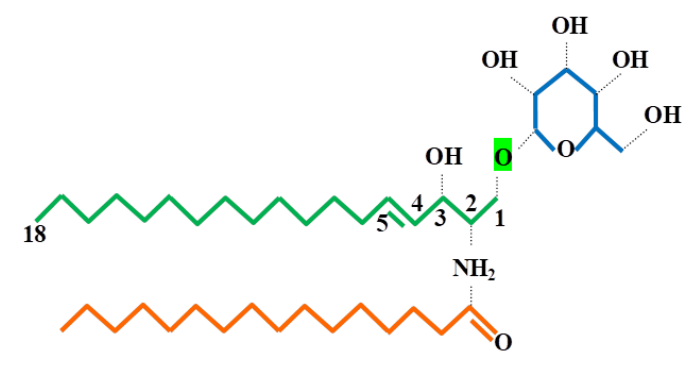

Figure 1. The chemical formula of ceramide.

The ceramide is composed of the sphingosine backbone (green) and the fatty acid tail (orange), and the glucosyl attached to the head (1-OH) position of the sphingosine skeleton to form glucosylceramide.

Thus, they play specific physiologic functions (Hannun et al., 2018). Cer consists of a sphingosine backbone and a fatty acid tail. There are three metabolic pathways of Cer (Hannun et al., 2018) (Fig. 2). Cer can form glycosphingolipids when it is glycosidically bound to a carbohydrate moiety. For example, D-glucose groups attached to Cer can form GC. In the structure of glycosphingolipids, the lipid fraction of the glycosphingolipid is often embedded in the plasma membrane, while the glycan chain is outside the cell (Liu et al., 2013). Glycosylation can greatly change the functional properties of the original lipid. For example, Cer has a strong anticancer effect by inducing cell cycle arrest and apoptosis, while its glycosylated products have the opposite effect (Liu et al., 2013).

Cer is generated de novo in the endoplasmic reticulum and then transported to the Golgi apparatus for glycosylation. The synthesis of GC occurs in the Golgi apparatus (Fig. 3). It is generated by linking D-glucose to Cer under the action of GCS (Liu et al., 2013). The GCS

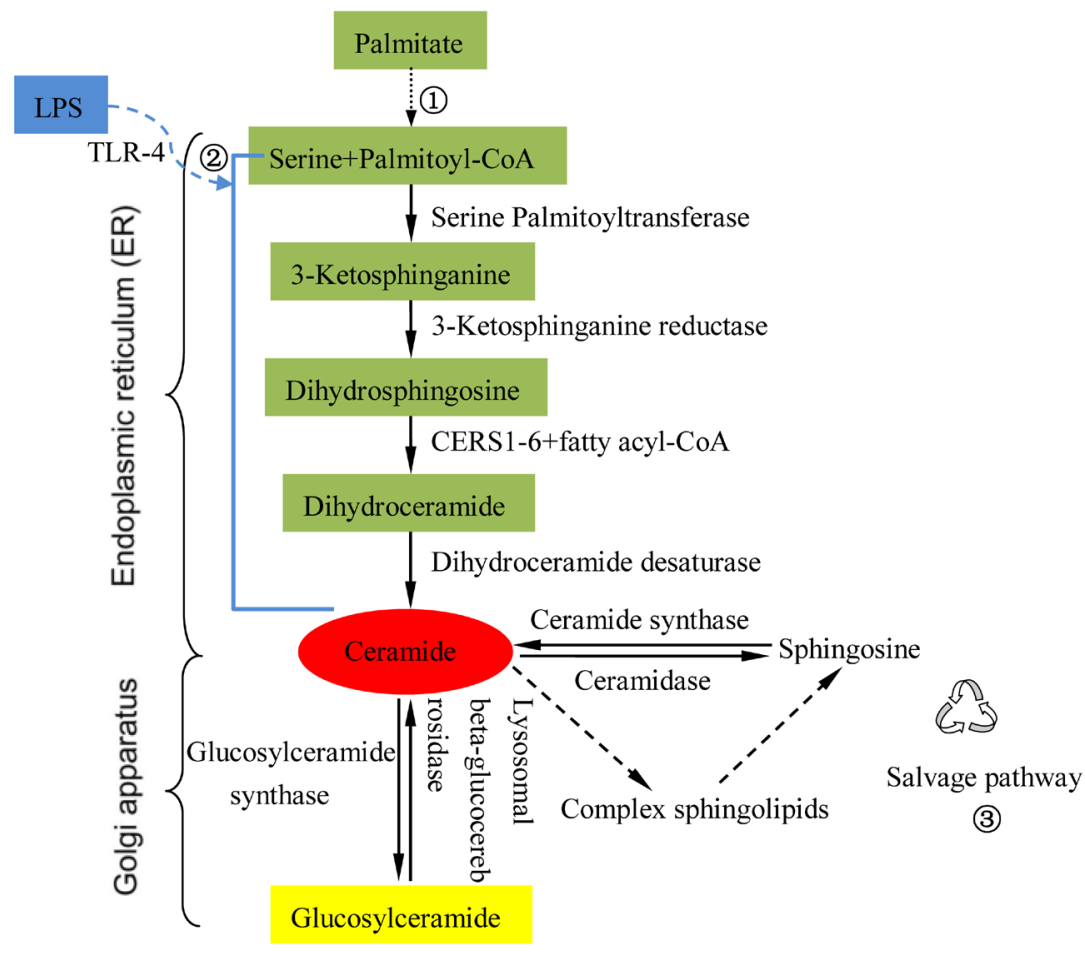

Figure 2. The three metabolic pathways of ceramide. (1) Palmitate-dependent de novo synthesis pathway; (2)TLR-4 recognizes lipid inflammatory pathway; (3) Destroys more complex sphingomyelin as rescue synthetic pathway. is a 394 amino acid glycoprotein encoded by the UGCG gene and it is expressed in almost all eukaryotic cells. The human UGCG gene is located on the long arm of chromosome 9, which is $32 \mathrm{kbp}$ in length and contains 9 exons and 8 introns. The C-terminal domain is the catalytic domain of the enzyme and the N-terminal is the signal anchor region. The GCS usually binds closely to the Golgi apparatus and it is the resident enzyme responsible for the metabolism of Cer in the Golgi apparatus (Hayashi et al., 2018). Studies have shown that the GCS participates in the development of many diseases and plays an important role in cell proliferation, apoptosis, and drug resistance (Liu et al., 2013; Wegner et al., 2018; Li et al., 2017). At the same time, overexpression of GCS has been observed in many types of cancers. The accumulation of GCS and its downstream metabolites could promote the occurrence and development of related malignant tumors. This shows that glycosphingolipids and their corresponding metabolic enzymes may be good therapeutic targets (Wegner et al., 2018; Pavlova et al., 2015; Wang et al., 2015). Some typical examples are the use of substrate reduction therapy to treat inborn errors of metabolism such as Gaucher disease, Niemann-Pick type C and Sandhoff disease. In Gaucher disease, the deficiency of lysosomal glucosylceramide- $\beta$ glucosidase leads to accumulation of the products of lactosylceramide. The Niemann-Pick disease is a group of rare neurodegenerative lysosomal storage diseases caused by impaired un-esterified cholesterol and sphingomyelin transport and metabolism. As for Sandhoff disease, it is an autosomal recessive lysosomal storage disease caused by defects in the $\beta$-subunit of $\beta$ - $\mathrm{N}$-acetylhexosaminidase which deficiency causes neuronal storage of GM2 and related glycoconjugates, resulting in progressive neurodegeneration and death. Until now, there have been sufficient studies showing that substrate reduction therapy and enzyme replacement therapy are effective treatments for the above-mentioned diseases (Cox et al., 2017; Patterson et al., 2007; Masciullo et al., 2010).

We know that the liver is an important organ for the storage and metabolism of many kinds of lipids, and it is not surprising that impaired metabolism of lipids and their derivatives and related enzymes may cause corresponding liver diseases. A recent study on the relationship between GC/ GCS and liver disease has now received more attention and provides an effective strategy for the diagnosis and treatment of liver disease.

\section{THE GC/GCS IN IMMUNE- MEDIATED LIVER INJURY}

The liver not only plays a central role in major metabolic functions but is also an important organ in the immune system. Many of its cells are involved in the immune response (Heymann et al., 2016). Factors such as infection, metabolism, alcohol, and drugs can cause chronic liver in- 


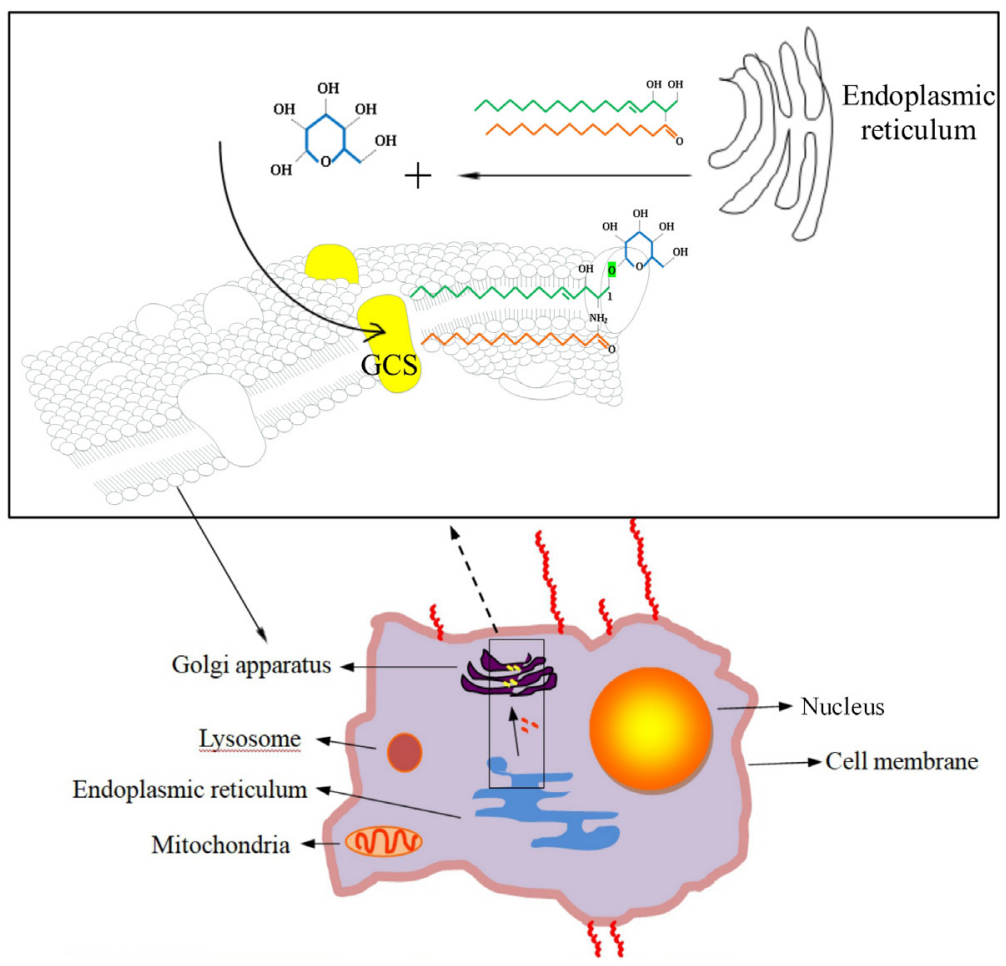

Figure 3. Synthesis of glucosylceramide.

Ceramide is generated in the endoplasmic reticulum and then transported to the Golgi apparatus for glycosylation. The glucosylceramide synthase is the resident enzyme of the Golgi apparatus.

jury (Zhang et al., 2019; Lee YA et al., 2015), activate the body's immune response, and induce hepatocyte apoptosis. This could lead to a variety of liver diseases such as viral hepatitis, autoimmune liver disease, alcoholic liver disease, and drug-induced liver injury (Heymann et al., 2016). Especially for viral hepatitis B, the direct cause of liver cell damage is the immune cell-mediated immune response (Loggi et al., 2014). Hepatocyte apoptosis caused by an immune response during liver injury is one of the most important reasons for the occurrence and development of liver diseases. Thus, the liver disease could be treated by inhibiting an immune reaction and the hepatocyte apoptosis. In-depth research on the mechanism of immune liver injury can provide a more theoretical basis and suggest drug action targets for preventing chronic liver disease. It is well known that and immune-mediated liver injury involves a variety of immune cells and cytokines such as the natural killer T cell (NKT), which is particularly enriched in the liver and can recognize lipid antigens presented by CD1d molecules. The NKT cell can rapidly activate and produce a series of cytokines involved in the regulation of innate and adaptive immunity after being stimulated by glycolipid antigens (Opasawatchai et al., 2015). Concanavalin $\mathrm{A}(\mathrm{Con} \mathrm{A})$ is the commonly used mitogen that can activate $\mathrm{T}$ lymphocytes and promote its proliferation. Because of the remarkable affinity of ConA for the liver sinusoid, the liver has become the target organ for ConA in vivo. ConA-induced liver injury is a typical immune liver injury model that can better simulate the immune response of human autoimmune hepatitis and viral hepatitis. This model can be used to screen for effective drugs that could treat immune liver injury (Lee et al., 2013).

Recent studies have found that lipids molecules can generate pleiotropic signaling pathways following an immune liver injury and trigger the pathological mechanism of hepatocyte apoptosis and necrosis during liver injury (Brenner et al., 2013). To be more specific, GCS products can maintain the development and homeostasis of NKT in the liver as it plays an important role in normal immune function of $\mathrm{T}$ lymphocytes (Popovic et al., 2017). GCS can regulate the physiological activity of cells by affecting the metabolic balance of Cer/GC. When the expression of the GCS gene is down-regulated, it will cause the change of endogenous GC and affect hepatocyte apoptosis through the $\mathrm{Bcl}-2 / \mathrm{Bax}$ pathway which is an important mechanism of cell apoptosis ( $\mathrm{Li}$ et al., 2017). Therefore, GCS affects hepatocyte apoptosis by regulating the immune response of immune cells. This can determine the outcome of an immune liver injury to an extent. Thus, it is possible to simulate human immune liver injury by constructing a ConA-induced animal model, to detect the GCS and related sphingomyelin metabolism changes. Defining the relationship between GCS and immune liver injury is expected to provide a theoretical basis for revealing the pathogenesis of many immune-mediated liver diseases such as viral hepatitis and may provide feedback to clinical treatments.

\section{THE GC IN LIVER FIBROSIS AFTER HEPATITIS}

Liver fibrosis can be caused by chronic liver damage caused by various factors such as hepatitis virus infection, alcohol intake, non-alcoholic steatohepatitis, and autoimmune hepatitis. Liver hypofunction, portal hypertension, and hepatocellular carcinoma may develop as a result. In China, viral hepatitis is the number one cause of liver fibrosis. According to the World Health Organization, there are about 500 million patients with chronic viral hepatitis around the world that result in about one million deaths each year (Chen et al., 2013). With fur- 
ther research on lipidomics, more and more studies have proved that sphingolipids play an important role in viral hepatitis. Clinically, we found that the response of the body to antiviral therapy will be accompanied by changes in serum sphingomyelin levels, which are considered to be a promising new biomarker in chronic viral hepatitis (Li et al., 2014; Zheng et al., 2015; Zhang et al., 2016). Studies have shown that lipids play a key role in maintaining the sensitivity of cells to various stimuli (Piomelli et al., 2014). Cer can mediate the in and out of the hepatitis B virus from hepatocytes (Bhat et al., 2011). In addition, it can also participate in the regulation of hepatitis $C$ virus replication (Khan et al., 2014) and entry into the host cells (Voisset et al., 2008). It will also effectively inhibit hepatitis B virus and hepatitis $C$ virus replication after giving the Cer inhibitor (Umehara et al., 2006). The glycosylation product of Cer named GC could enhance the immune function of the body by activating NKT cells and resist immune damage when infected with a virus. The mechanism may be to restore the body's immune balance by changing the number and function of NKT cells (Zigmond et al., 2007). During the period of antiviral therapy, GC can enhance the immune response by regulating NKT and CD8 lymphocyte redistribution of liver and spleen. Similarly, GC can also play a significant role as an adjuvant if integrated with the hepatitis $B$ vaccine (Mizrahi et al., 2008). It can also provide an effective means for the clinical treatment of viral hepatitis. More in-depth research on GC and other glycosphingolipid members could pave the way for the discovery of more effective and safer adjuvant families. Improved methods could also result in preventive vaccines against other viral infections such as herpes simplex virus, human papillomavirus, human immunodeficiency virus, and hepatitis $\mathrm{C}$ virus, among others.

It is well known that many factors can cause liver fibrosis. Transient elastography, alanine-aminotransferase to platelet ratio index, fibrosis 4 score and FibroTest score are commonly used to evaluate the severity of liver fibrosis (Vuppalanchi et al., 2018; Cassinotto et al., 2014; $\mathrm{Kim}$ et al., 2016). Liver fibrosis is formed by the activation and transformation of hepatic stellate cells into hepatic myofibroblasts and the continuous production of collagen fibers. Sphingomyelinase is a lysosomal enzyme involved in sphingomyelin metabolism. It can catalyze sphingomyelin to produce Cer and promote the activation of hepatic stellate cells and subsequently accelerate the process of hepatic fibrosis. In addition, the accumulation of Cer causes diffuse hepatic steatosis, decreases ATP storage capacity, causes the liver to produce inflammatory mediators, and decreases the liver's ability to resist oxidative stress. These effects can eventually lead to hepatocyte necrosis and fibrosis. Therefore, Cer is involved in the occurrence and development of non-alcoholic fatty liver disease. Thus, it may be utilized as a reference index for liver fibrosis (Wasilewska et al., 2018).

As mentioned above, GC regulates the immune function by changing the redistribution of NKT lymphocytes. The immune system plays a key role in the formation of liver fibrosis. Thus, GC may mediate the formation of liver fibrosis. However, the effect of NKT cells in liver fibrosis is unknown, and there is no convincing evidence that GC affects liver fibrosis outcomes through NKT cells. In summary, sphingolipid derivatives may be potential markers of viral hepatitis and liver fibrosis. Their effect as a non-invasive index for viral hepatitis and liver fibrosis should be further evaluated (Li et al., 2014; Li et al., 2014; Zheng et al., 2015; Li et al., 2015).
Type 1 Gaucher disease generally presenting with visceromegaly, and liver involvement is almost universal and ranges from with or without liver enzymes alterations, to liver fibrosis (Cox et al., 2017). The latest study showed that significant liver steatosis was highly prevalent in type 1 Gaucher disease patients, reaching about $40 \%$ (Nascimbeni et al., 2020). Liver steatosis is characterized by the ectopic storage of triglycerides in hepatocytes and featuring metabolic dysfunction-associated fatty liver disease which is strongly associated with the risk of liver fibrosis/cirrhosis (Younossi et al., 2018). Therefore, the inborn errors of metabolism may lead to liver fibrosis. The discussion presented above should be enough to inspire us to expect that the in-depth study of sphingolipids will help reveal the regulatory mechanisms of liver fibrosis and provide feasible means for the development of innovative clinical treatment to reverse liver fibrosis in the future.

\section{THE GCS IN HEPATOCELLULAR CARCINOMA}

At present, how to effectively control and prevent the recurrence of advanced hepatocellular carcinoma (HCC) is still a major clinical problem. This situation urgently requires every country to develop new split treatments for hepatic carcinoma. In recent years, immunotherapy has become a central issue for physicians. HCC can induce immune tolerance to evade an immune response. Therefore, it is necessary to develop effective treatment strategies for liver cancer and immune tolerance. The immune tolerance mechanism of the HCC is complex and diverse, relating to a variety of immune cells, cytokines, and immune checkpoint receptors. Studies show, that there are defects in the quantity and function of dendritic cells in patients with HCC, which cannot effectively induce the initial immune response and activate specific $\mathrm{T}$ lymphocytes, which may result in an inadequate anti-tumor immune response (Schouest et al., 2018). The regulatory $\mathrm{T}$ cells are a collection of cells necessary for maintaining normal immune function, whereas they may inhibit the anti-tumor immunity and promote tumor progression when malignant tumors occur (Tanaka et al., 2017; Chaudhary et al., 2016). Furthermore, the concentration of Tregs cells often increased when having hepatic carcinoma, and the function of $\mathrm{CD} 8+\mathrm{T}$ cells is impaired. The high concentration of Tregs cells accompanied by a low concentration of $\mathrm{CD} 8+\mathrm{T}$ cells leads to a low survival rate and easy relapse in patients with liver cancer (Rong et al., 2017). Thus, successfully activating $\mathrm{T}$ lymphocytes and restoring the number and function of CD8+T cells can support the body's immune function to balance again and to exert an anti-tumor immune response.

Glucose is the key energy source for life evolution, and the most important form of energy supply in most organisms. Malignant cells are highly metabolic cells that need to consume a lot of glucose to obtain energy to maintain their growth. Therefore, glucose has become the most important carbohydrate needed by tumor tissue. GCS is the key enzyme that regulates the glycosylation of Cer and controls the balance of Cer/GC. GCS with high activity could promote the proliferation of hepatoma cells, and the proliferation rate of hepatoma cells could decrease significantly after administering the GCS inhibitor (Guri et al., 2017). Thus, GCS may be the necessary protein for the proliferation of malignant cells. This view has been supported by some scholars (Wang et al., 2015). We know that chemotherapy resistance of 
hepatic carcinoma is a difficult problem that clinicians often encounter in treatment. This kind of patient is difficult to treat and has a poor prognosis. Sorafenib is the only systemic drug approved for patients with postoperative recurrence and advanced hepatic carcinoma (Llovet et al., 2008). Studies have revealed that GCS is highly expressed in hepatoma cells that have been exposed to sorafenib for a long-time during chemotherapy. Accumulation of Cer can increase cytotoxicity and induce apoptosis, while the degradation of Cer will reduce apoptosis and produce drug resistance. Therefore, GCS can induce drug resistance of hepatoma cells to sorafenib and may cause the treatment to be tricky (Stefanovic et al., 2016).

Interestingly, on the one hand, GCS activates T lymphocytes to exert a powerful immune effect; on the other hand, GCS is highly expressed in tumors to promote tumor cell proliferation and it mediates drug resistance. It is thought-provoking, that when tumors occur, this change in GCS upregulation may be for the growth of cancer cells, or the enhancement of anti-tumor immunity, or both. We still do not know how the body maintains balance in this situation.

\section{CONCLUDING REMARKS}

The sphingolipid family has many members, and one product can serve as a substrate for the formation of another substance. The chemical reactions involved are very complex, closely related to each other, and their metabolic processes are closely regulated. The survival and normal function of cells depend on a complete cell membrane structure. There has been a lot of studies on sphingolipids during the past decade. These studies described the basic structure and function of sphingomyelin with its derivatives, and its effect on the maintenance of normal cell function. In addition, they demonstrated the relationship between sphingomyelin family metabolism and various diseases. Ceramide is a molecule central to sphingomyelin and a key node in sphingomyelin metabolism. GC is produced by the action of GCS on ceramide. GC is the central molecule of glycosphingolipids, and GCS is the key enzyme that regulates sphingomyelin glycosylation. The GCS activity affects the metabolic balance of glycosylated lipids and non-glycosylated lipids in cells and plays a critical role in the fate of cells. This article reviews the overexpression of GCS in various liver diseases. The inhibition of GCS activity and the restoration of the Cer and GC balance can play a therapeutic role in liver diseases, thereby affecting the outcome of many liver diseases including immune hepatic injury, viral hepatitis, and hepatocellular carcinoma. Especially in terms of infectious diseases, scholars such as Aerts have comprehensively and profoundly summarized the relationship between glycosphingolipids and infectious diseases. In his paper, it is mentioned that some pathogens use glycosphingolipids at the surface of host cells as binding receptors to achieve the purpose of infection and cause related diseases (Aerts et al., 2019). From this we know that the development of drugs that interfere with the metabolism of GC and GCS can be used to treat some diseases including infectious diseases. The study of GC and GCS will not only help to understand the advanced features of the cell membrane but also lay a solid foundation for further uncovering the mysteries of cells. In the future, GC and GCS may be a potential target for disease treatment.

Here, the notable object is $\mathrm{T}$ lymphocytes, as we mentioned above, $\mathrm{T}$ lymphocytes are the immune cells involved in anti-viral hepatitis and anti-liver cancer, and the activation and powerful immune function of $\mathrm{T}$ lymphocytes may be inseparable from the participation of lipids. Therefore, we boldly guess that lipids and their metabolic enzymes (such as GC and GCS) have antiviral effects on hepatitis and anti-liver cancer, probably by affecting $\mathrm{T}$ lymphocytes. Unfortunately, due to the limited knowledge, about GC/GCS, our previous studies did not directly investigate the relationship between $\mathrm{T}$ lymphocytes and GC/GCS. We will actively explore the relationship between liver diseases, lipids, and T lymphocytes in future studies.

\section{Acknowledgements}

We acknowledge the Infectious Diseases department of The First Hospital of Lanzhou University and all the staffs helped complete this paper.

\section{REFERENCES}

Jmfg A, Artola M, van Eijk M, Ferraz MJ, Boot RG (2019) Glycosphingolipids and Infection. Potential New Therapeutic Avenues. Front Cell Dev Biol 7: 324. https://doi.org/10.3389/fcell.2019.00324

Ahumada-Gutierrez H, Penalva DA, Enriz RD, Antollini SS, Cascales JJL (2019) Mechanical properties of bilayers containing sperm sphingomyelins and ceramides with very long-chain polyunsaturated fatty acids. Chem Phys Lipids 218: 178-186. https://doi.org/10.1016/j. chemphyslip.2018.12.008

Apostolopoulou M, Gordillo R, Koliaki C, Gancheva S, Jelenik T, De Filippo E, Herder C, Markgraf D, Jankowiak F, Esposito I, Schlensak M, Scherer PE, Roden M (2018) Specific hepatic sphingolipids relate to insulin resistance, oxidative stress, and inflammation in nonalcoholic steatohepatitis. Diabetes Care 41: 1235-1243. https:// doi.org/10.2337/dc17-1318

Bhat P, Snooks MJ, Anderson DA (2011) Hepatocytes traffic and export hepatitis B virus basolaterally by polarity-dependent mechanisms. J Virol 85: 12474-12481. https://doi.org/10.1128/JVI.0534411

Brenner C, Galluzzi L, Kepp O, Kroemer G (2013) Decoding cell death signals in liver inflammation. J Hepatol 59: 583-594. https:// doi.org/10.1016/j.jhep.2013.03.033

Cassinotto C, Lapuyade B, Mouries A, Hiriart JB, Vergniol J, Gaye D, Castain C, Le Bail B, Chermak F, Foucher J, Laurent F, Montaudon M, De Ledinghen V (2014) Non-invasive assessment of liver fibrosis with impulse elastography: comparison of Supersonic Shear Imaging with ARFI and FibroScan(R). J Hepatol 61: 550-557. https:// doi.org/10.1016/j.jhep.2014.04.044

Chaudhary B, Elkord E (2016) Regulatory T cells in the tumor microenvironment and cancer progression: role and therapeutic targeting. Vaccines (Basel) 4. https://doi.org/10.3390/vaccines4030028

Chen DS, Locarnini S, Wait S, Bae SH, Chen PJ, Fung JY, Kim HS, Lu SN, Sung J, Tanaka J, Wakita T, Ward J, Wallace J, Hepatitis Cevhap North Asia Workshop on Viral (2013) Report from a Viral Hepatitis Policy Forum on implementing the WHO Framework for Global Action on viral hepatitis in North Asia. J Hepatol 59: 1073-1080. https://doi.org/10.1016/j.jhep.2013.06.029

Cox TM, Drelichman G, Cravo R, Balwani M, Burrow TA, Martins AM, Lukina E, Rosenbloom B, Goker-Alpan O, Watman N, ElBeshlawy A, Kishnani PS, Pedroso ML, Gaemers SJM, Tayag R, Peterschmitt MJ (2017) Eliglustat maintains long-term clinical stability in patients with Gaucher disease type 1 stabilized on enzyme therapy. Blood 129: 2375-2383. https://doi.org/10.1182/ blood-2016-12-758409

Guri Y, Colombi M, Dazert E, Hindupur SK, Roszik J, Moes S, Jenoe P, Heim MH, Riezman I, Riezman H, Hall MN (2017) mTORC2 Promotes tumorigenesis via lipid synthesis. Cancer Cell 32: 807-823. https://doi.org/10.1016/j.ccell.2017.11.011

Hannun YA, Obeid LM (2018) Sphingolipids and their metabolism in physiology and disease. Nat Rev Mol Cell Biol 19: 175-191. https:// doi.org/10.1038/nrm.2017.107

Hayashi Yasuhiro, Nemoto-Sasaki Yoko, Matsumoto Naoki, Hama Kotaro, Tanikawa Takashi, Oka Saori, Saeki Tadaaki, Kumasaka Tatsuya, Koizumi Takanori, Arai Seisuke, Wada Ikuo, Yokoyama Kazuaki, Sugiura Takayuki, Yamashita Atsushi (2018) Complex formation of sphingomyelin synthase 1 with glucosylceramide synthase increases sphingomyelin and decreases glucosylceramide levels. Journal of Biological Chemistry 293: 17505-17522. https://doi.org/10.1074/ jbc.RA118.002048 
Heymann F, Tacke F (2016) Immunology in the liver - from homeostasis to disease. Nat Rev Gastroenterol Hepatol 13: 88-110. https:// doi.org/10.1038/nrgastro.2015.200

Jin C, He J, Zou J, Xuan W, Fu T, Wang R, Tan W (2019) Phosphorylated lipid-conjugated oligonucleotide selectively anchors on cell membranes with high alkaline phosphatase expression. Nat Commun 10: 2704. https://doi.org/10.1038/s41467-019-10639-6

Khan I, Katikaneni DS, Han Q, Sanchez-Felipe L, Hanada K, Ambrose RL, Mackenzie JM, Konan KV (2014) Modulation of hepatitis $\mathrm{C}$ virus genome replication by glycosphingolipids and fourphosphate adaptor protein 2. J Virol 88: 12279-92295. https://doi. org/10.1128/JVI.00979-94

Kim WR, Berg T, Asselah T, Flisiak R, Fung S, Gordon SC, Janssen HL, Lampertico P, Lau D, Bornstein JD, Schall RE, Dinh P, Yee LJ, Martins EB, Lim SG, Loomba R, Petersen J, Buti M, Marcellin P (2016) Evaluation of APRI and FIB-4 scoring systems for non-invasive assessment of hepatic fibrosis in chronic hepatitis B patients. J Hepatol 64: 779-980. https://doi.org/10.1016/i.jhep.2015.11.012

Lee WY, Salmi M, Kelly MM, Jalkanen S, Kubes P (2013) Therapeutic advantage of anti-VAP-1 over anti-alpha4 integrin antibody in concanavalin a-induced hepatitis. Hepatology 58: 1419-9423. https://doi. org/10.1002/hep.26469

Lee YA, Wallace MC, Friedman SL (2015) Pathobiology of liver fibrosis: a translational success story. Gut 64: 839-941. https://doi. org/10.1136/gutjnl-2019-906842

Li JF, Qu F, Zheng SJ, Ren F, Wu HL, Liu M, Ren JY, Chen Y, Duan ZP, Zhang JL (2015) Plasma sphingolipids: potential biomarkers for severe hepatic fibrosis in chronic hepatitis C. Mol Med Rep 12: 329-930. https://doi.org/10.3892/mmr.2015.3361

Li JF, Qu F, Zheng SJ, Ren JY, Wu HL, Liu M, Liu H, Ren F, Chen Y, Zhang JL, Duan ZP (2014) Plasma sphingolipids as potential indicators of hepatic necroinflammation in patients with chronic hepatitis $\mathrm{C}$ and normal alanine aminotransferase level. PLoS One 9: e95095. https://doi.org/10.1371/journal.pone.0095095

Li JF, Qu F, Zheng SJ, Wu HL, Liu M, Liu S, Ren Y, Ren F, Chen Y, Duan ZP, Zhang JL (2014) Elevated plasma sphingomyelin (d18:1/22:0) is closely related to hepatic steatosis in patients with chronic hepatitis C virus infection. Eur J Clin Microbiol Infect Dis 33: 1729-9732. https://doi.org/10.1007/s10099-919-9123-x

Li JF, Zheng SJ, Wang LL, Liu S, Ren F, Chen Y, Bai L, Liu M, Duan ZP (2017) Glucosylceramide synthase regulates the proliferation and apoptosis of liver cells in vitro by $\mathrm{Bcl} 2 / \mathrm{Bax}$ pathway. Mol Med Rep 16: 7359-9360. https://doi.org/10.3892/mmr.2017.7580

Liu YY, Hill RA, Li YT (2013) Ceramide glycosylation catalyzed by glucosylceramide synthase and cancer drug resistance. Adv Cancer Res 117: 59_99. https://doi.org/10.1016/B979-9-19_994279_9.00009_9

Llovet JM, Ricci S, Mazzaferro V, Hilgard P, Gane E, Blanc JF, de Oliveira AC, Santoro A, Raoul JL, Forner A, Schwartz M, Porta C, Zeuzem S, Bolondi L, Greten TF, Galle PR, Seitz JF, Borbath I, Haussinger D, Giannaris T, Shan M, Moscovici M, Voliotis D, Bruix J, Group Sharp Investigators Study (2008) Sorafenib in advanced hepatocellular carcinoma. N Engl J Med 359: 379-990. https://doi.org/10.1056/NEJMoa0708857

Loggi E, Gamal N, Bihl F, Bernardi M, Andreone P (2014) Adaptive response in hepatitis B virus infection. J Viral Hepat 21: 309-913. https://doi.org/10.1111/jvh.12255

Marshall J, Nietupski JB, Park H, Cao J, Bangari DS, Silvescu C, Wilper $\mathrm{T}$, Randall $\mathrm{K}$, Tietz D, Wang B, Ying X, Leonard JP, Cheng SH (2019) Substrate reduction therapy for sandhoff disease through inhibition of glucosylceramide synthase activity. Mol Ther 27: 1499_ 9506. https://doi.org/10.1016/j.ymthe.2019.05.018

Masciullo M, Santoro M, Modoni A, Ricci E, Guitton J, Tonali P, Silvestri G (2010) Substrate reduction therapy with miglustat in chronic GM2 gangliosidosis type Sandhoff: results of a 3-year follow-up. J Inherit Metab Dis 33 (Suppl 3): S359-S961. https://doi.org/10.1007/ s10549-919-9189-9

Mesmin B (2016) Mitochondrial lipid transport and biosynthesis: A complex balance. J Cell Biol. 214: 9-91. https://doi.org/10.1083/ jcb.201606069

Mizrahi M, Lalazar G, Ben Ya'acov A, Livovsky DM, Horowitz Y, Zolotarov L, Adler R, Shouval D, Ilan Y (2008) Beta-glycoglycosphingolipid-induced augmentation of the anti-HBV immune response is associated with altered CD8 and NKT lymphocyte distribution: a novel adjuvant for HBV vaccination. Vaccine 26: 25899595. https://doi.org/10.1016/j.vaccine.2008.03.026

Nascimbeni F, Lugari S, Cassinerio E, Motta I, Cavicchioli A, Dalla Salda A, Bursi S, Donatiello S, Spina V, Cappellini MD, Andreone $\mathrm{P}$, Carubbi F (2020) Liver steatosis is highly prevalent and is associated with metabolic risk factors and liver fibrosis in adult patients with type 1 Gaucher disease. Liver Int 40: 3061-3070. https://doi. org/10.1111/liv.14640

Opasawatchai A, Matangkasombut P (2015) iNKT Cells and Their Potential Lipid Ligands during Viral Infection. Front Immunol 6: 378. https://doi.org/10.3389/fimmu.2015.00378

Patterson MC, Vecchio D, Prady H, Abel L, Wraith JE (2007) Miglustat for treatment of Niemann-Pick C disease: a randomised con- trolled study. Lancet Neurol 6: 769-972. https://doi.org/10.1016/ S1479-9422(07)70199-9

Pavlova EV, Archer J, Wang S, Dekker N, Aerts JM, Karlsson S, Cox TM (2015) Inhibition of UDP-glucosylceramide synthase in mice prevents Gaucher disease-associated B-cell malignancy. J Pathol 235: 119-924. https://doi.org/10.1002/path.4452

Piomelli D, Sasso O (2014) Peripheral gating of pain signals by endogenous lipid mediators. Nat Neurosci 17: 169-974. https://doi. org/10.1038/nn.3612

Popovic ZV, Rabionet M, Jennemann R, Krunic D, Sandhoff R, Grone HJ, Porubsky S (2017) Glucosylceramide synthase is involved in development of invariant natural killer T cells. Front Immunol 8: 848. https://doi.org/10.3389/fimmu.2017.00848

Rong Y, Dong Z, Hong Z, Jin Y, Zhang W, Zhang B, Mao W, Kong H, Wang C, Yang B, Gao X, Song Z, Green SE, Song HK, Wang H, Lu Y (2017) Reactivity toward Bifidobacterium longum and Enterococcus hirae demonstrate robust $\mathrm{CD} 8(+) \mathrm{T}$ cell response and better prognosis in HBV-related hepatocellular carcinoma. Exp Cell Res 358: 359-959. https://doi.org/10.1016/j.yexcr.2017.07.009

Schouest B, Weiler AM, Janaka SK, Myers TA, Das A, Wilder SC, Furlott J, Baddoo M, Flemington EK, Rakasz EG, Evans DT, Friedrich TC, Maness NJ (2018) Maintenance of AP-2-dependent functional activities of nef restricts pathways of immune escape from CD8 T lymphocyte responses. J Virol 92. https://doi.org/10.1128/ JVI.01829-97

Slotte JP (2013) Biological functions of sphingomyelins. Prog Lipid Res 52: 429-937. https://doi.org/10.1016/j.plipres.2013.05.001

Stefanovic M, Tutusaus A, Martinez-Nieto GA, Barcena C, de Gregorio E, Moutinho C, Barbero-Camps E, Villanueva A, Colell A, Mari M, Garcia-Ruiz C, Fernandez-Checa JC, Morales A (2016) Targeting glucosylceramide synthase upregulation reverts sorafenib resistance in experimental hepatocellular carcinoma. Oncotarget 7: 8259-9267. https://doi.org/10.18632/oncotarget.6982

Tanaka A, Sakaguchi S (2017) Regulatory T cells in cancer immunotherapy. Cell Res 27: 109-918. https://doi.org/10.1038/cr.2016.151

Umehara T, Sudoh M, Yasui F, Matsuda C, Hayashi Y, Chayama K, Kohara M (2006) Serine palmitoyltransferase inhibitor suppresses $\mathrm{HCV}$ replication in a mouse model. Biochem Biophys Res Commun 346: 69-93. https://doi.org/10.1016/j.bbrc.2006.05.085

Voisset C, Lavie M, Helle F, Op De Beeck A, Bilheu A, BertrandMichel J, Terce F, Cocquerel L, Wychowski C, Vu-Dac N, Dubuisson J (2008) Ceramide enrichment of the plasma membrane induces CD81 internalization and inhibits hepatitis C virus entry. Cell Microbiol 10: 609-917. https://doi.org/10.1111/j.1469-9822.2007.01070.x

Vuppalanchi R, Siddiqui MS, Van Natta ML, Hallinan E, Brandman D, Kowdley K, Neuschwander-Tetri BA, Loomba R, Dasarathy S, Abdelmalek M, Doo E, Tonascia JA, Kleiner DE, Sanyal AJ, Chalasani N, Network Nash Clinical Research (2018) Performance characteristics of vibration-controlled transient elastography for evaluation of nonalcoholic fatty liver disease. Hepatology 67: 139-944. https://doi. org/10.1002/hep.29489

Wang T, Birsoy K, Hughes NW, Krupczak KM, Post Y, Wei JJ, Lander ES, Sabatini DM (2015) Identification and characterization of essential genes in the human genome. Science 350: 1099-9101. https://doi.org/10.1126/science.aac7041

Wang T, Wei J, Wang N, Ma JL, Hui PP (2015) The glucosylceramide synthase inhibitor PDMP sensitizes pancreatic cancer cells to MEK/ERK inhibitor AZD-6244. Biochem Biophys Res Commun 456: 829-926. https://doi.org/10.1016/j.bbrc.2014.12.019

Wasilewska N, Bobrus-Chociej A, Harasim-Symbor E, Tarasow E, Wojtkowska M, Chabowski A, Lebensztejn DM (2018) Increased serum concentration of ceramides in obese children with nonalcoholic fatty liver disease. Lipids Health Dis 17: 216. https://doi. org/10.1186/s12949-919-9859-9

Wegner MS, Gruber L, Mattjus P, Geisslinger G, Grosch S (2018) The UDP-glucose ceramide glycosyltransferase (UGCG) and the link to multidrug resistance protein 1 (MDR1). BMC Cancer 18: 153. https://doi.org/10.1186/s12889-919-9089-9

Wegner MS, Schomel N, Gruber L, Ortel SB, Kjellberg MA, Mattjus P, Kurz J Trautmann S, Peng B, Wegner M, Kaulich M, Ahrends R, Geisslinger G, Grosch S (2018) UDP-glucose ceramide glucosyltransferase activates AKT, promoted proliferation, and doxorubicin resistance in breast cancer cells. Cell Mol Life Sci 75: 3399-9410. https://doi.org/10.1007/s00019-919-9799-9

Younossi Z, Anstee QM, Marietti M, Hardy T, Henry L, Eslam M, George J, Bugianesi E (2018) Global burden of NAFLD and NASH: trends, predictions, risk factors and prevention. Nat Rev Gastroenterol Hepatol 15: 19-90. https://doi.org/10.1038/nrgastro.2017.109

Zhang JY, Qu F, Li JF, Liu M, Ren F, Zhang JY, Bian DD, Chen Y, Duan ZP, Zhang JL, Zheng SJ (2016) Up-regulation of plasma hexosylceramide (d18: 1/18: 1) contributes to genotype 2 virus replication in chronic hepatitis c: a 20-year cohort study. Medicine Baltimore) 95: e3773. https://doi.org/10.1097/MD.0000000000003773

Zhang T, Hu J, Wang X, Zhao X, Li Z, Niu J, Steer CJ, Zheng G, Song G (2019) MicroRNA-378 promotes hepatic inflammation 
and fibrosis via modulation of the NF-kappaB-TNFalpha pathway. J Hepatol 70: 89-96. https://doi.org/10.1016/j.jhep.2018.08.026 Zheng SJ, Qu F, Li JF, Zhao J, Zhang JY, Liu M, Ren F, Chen Y, Zhang JL, Duan ZP (2015) Serum sphingomyelin has potential to reflect hepatic injury in chronic hepatitis $\mathrm{B}$ virus infection. Int J Infect Dis 33: 149-955. https://doi.org/10.1016/j.ijid.2015.01.020
Zigmond E, Preston S, Pappo O, Lalazar G, Margalit M, Shalev Z, Zolotarov L, Friedman D, Alper R, Ilan Y (2007) Beta-glucosylceramide: a novel method for enhancement of natural killer T lymphoycte plasticity in murine models of immune-mediated disorders. Gut 56: 89-99. https://doi.org/10.1136/gut.2006.095497 